\title{
Is there a differential impact of parity on factors regulating maternal peripheral resistance?
}

\begin{abstract}
Makoto Iizuka $^{1,2}$, Naoyuki Miyasaka ${ }^{1}$, Yuki Hirose ${ }^{1}$, Mikayo Toba $^{1}$, Shuichi Sakamoto ${ }^{2}$ and Toshiro Kubota ${ }^{1}$
Parity may influence cardiovascular adaptations during pregnancy. However, little is known about the influence of parity on maternal hemodynamic adaptations. In this prospective study, we investigated factors regulating peripheral resistance that control hemodynamic adaptations in pregnant women and evaluated differences in these factors between nulliparous and multiparous women. We evaluated 127 patients (nulliparous: 78, multiparous: 49) without any complications and not taking medications and assessed hemodynamics, arterial stiffness, modified flow-mediated dilation (MFMD) and heart rate variability, including power spectral and detrended fluctuation analysis (DFA). Diastolic blood pressure (BP) was significantly higher in nulliparous than multiparous women throughout pregnancy $(P<0.05)$. Diastolic BP was significantly higher in nulliparous than multiparous women in the third trimester (95\% confidence interval (Cl), 2.43-9.73). A significant difference in high-frequency power was observed between nulliparous and multiparous $(P<0.05)$ women, and was significantly lower in multiparous than nulliparous women in the third trimester $(95 \% \mathrm{Cl}, 0.74-0.34)$. The low-frequency/high-frequency ratio was significantly increased in both groups between the first trimester and the third trimester $(P<0.05)$. The DFA value, $\alpha 2$, significantly differed between nulliparous and multiparous $(P<0.05)$, and was significantly lower in nulliparous than multiparous women $(95 \% \mathrm{Cl},-0.30$ to -0.10$)$. The $\mathrm{mFMD}$ and arterial stiffness remained approximately the same for nulliparous and multiparous women for all trimesters. Our results suggested that nulliparous women were characterized by greater autonomic nervous activity than were multiparous women.
\end{abstract}

Hypertension Research (2016) 39, 737-743; doi:10.1038/hr.2016.60; published online 23 June 2016

Keywords: flow-mediated dilation; heart rate variability; hemodynamics; parity; pregnancy

\section{INTRODUCTION}

The maternal hemodynamic system undergoes profound changes during pregnancy. ${ }^{1-6}$ These adaptations include an initial decrease in systemic vascular tone, an increase in cardiac output and an expansion of plasma volume, leading to a gradual decrease in systolic and diastolic blood pressure (BP) until mid-pregnancy, when BP increases through delivery. ${ }^{7}$ Maternal hemodynamic maladaptations may occur because of maternal complications, although the underlying mechanisms are not fully known.

Parity may influence cardiovascular adaptations during pregnancy. ${ }^{7-9}$ BP has been found to be higher in nulliparous women than in multiparous women. ${ }^{7,10}$ However, results in this area are not consistent. ${ }^{8}$ Thus, little is known about the influence of parity on maternal hemodynamic adaptations.

Arterial BP is primarily regulated by the cardiovascular, autonomic nervous and vascular systems. ${ }^{2}$ Among them, the vascular system plays an important role in regulating maternal BP for the reasons noted above. Total peripheral resistance is regulated via vascular endothelial cell function, arterial stiffness, autonomic nervous function and hormonal factors. Although these factors have been reported to change during pregnancy, ${ }^{5,11-14}$ the impact of parity on them remains unclear.

There are noninvasive methods for evaluating factors regulating peripheral resistance. Flow-mediated dilation (FMD) is a simple and noninvasive measure of endothelial capacity. When the endothelium is stimulated by a sudden increase in shear stress, it causes smooth muscle cell relaxation and vasodilation. ${ }^{15,16}$ Arterial compliance and pulse wave velocity (PWV) are assessed to evaluate the elastic behavior of arterial segments in vivo. These are simple and reproducible methods for determining arterial stiffness. ${ }^{17}$ The measurement of spectral heart rate variability (HRV) is a noninvasive measure of autonomic nervous function. It has been demonstrated to have diagnostic and prognostic value in many physiological and pathological conditions. ${ }^{18,19}$

In this prospective study, we investigated factors regulating peripheral resistance that control hemodynamic adaptation in pregnant women and evaluated differences in these factors between nulliparous and multiparous women.

\footnotetext{
${ }^{1}$ Comprehensive Reproductive Medicine, Graduate School, Tokyo Medical and Dental University, Tokyo, Japan and ${ }^{2}$ Department of Obstetrics/Gynecology, Dokkyo Medical University Koshigaya Hospital, Saitama, Japan

Correspondence: Dr M lizuka, Comprehensive Reproductive Medicine, Graduate School, Tokyo Medical and Dental University (TMDU), 1-5-45, Yushima, Bunkyo-ku, Tokyo 113-8519, Japan.

E-mail: makocrm@tmd.ac.jp

Received 5 September 2015; revised 26 March 2016; accepted 14 April 2016; published online 23 June 2016
} 


\section{METHODS}

\section{Subjects}

In this prospective study, participants were recruited from the Department of Obstetrics and Gynecology, Tokyo Medical and Dental University between September 2011 and November 2012. Those who were diagnosed with diabetes mellitus, hypertension, cardiovascular diseases and/or psychological disease; had multiple conceptions; and were taking any medications were excluded. The present study included 78 nulliparous (32.4 \pm 4.9 years) and 49 multiparous ( $33.7 \pm 4.1$ years) pregnant women. Repeat measurements were performed in several women during the third trimester. In order to compare factors involved in the regulation of peripheral resistance between the two groups of women, these measures were averaged and counted as a single observation. The details of the women are described in Tables 1 and 2. The present study was approved by the medical ethics committee of Tokyo Medical and Dental University. All procedures performed in studies involving human participants were in accordance with the ethical standards of the institutional and/or national research committee and with the 1964 Helsinki Declaration and its later amendments or comparable ethical standards. Informed consent was obtained from all individual participants included in the study.

\section{Modified flow-mediated dilation}

Endothelial function was noninvasively assessed using modified flow-mediated dilation (mFMD), as in previous studies. ${ }^{15,16}$ Participants were examined while in a supine position after $>5 \mathrm{~min}$ of rest in a quiet and temperature-controlled $\left(22-25^{\circ} \mathrm{C}\right)$ room. The mFMD measurement of the brachial artery was evaluated by amplitude and brightness mode ultrasonography with the use of a linear array 10-MHz transducer (UNEXEF18G, UNEX, Nagoya, Japan). After baseline diameter measurements for $30 \mathrm{~s}$, a BP cuff was inflated to $50 \mathrm{~mm} \mathrm{Hg}$ above the patient's systolic BP for $5 \mathrm{~min}$, and then deflated. The diameter of the brachial artery was continuously recorded for $2 \mathrm{~min}$ after the cuff was deflated. All diameters were measured in the end-diastolic phase, defined as the beginning of the $\mathrm{R}$ wave on electrocardiography. The timing of the occluded base and maximum arterial diameter measurements were as previously described. ${ }^{15,16}$ The mFMD was calculated using the following parameters: $\mathrm{mFMD}=(($ Drep - Dinfl $) /$ Dinfl $) \times 100 \%$, where Dinfl is the lowest end-diastolic diameter during cuff inflation measured immediately after release and Drep is the highest peak end-diastolic diameters during reperfusion.

\section{Table 1 Patient characteristics}

\begin{tabular}{lccc}
\hline Parameter & Nulliparous $(\mathrm{N}=78)$ & Multiparous $(\mathrm{N}=49)$ & P-value \\
\hline Maternal age (years) & $32.4 \pm 4.9$ & $33.7 \pm 4.1$ & $\mathrm{NS}$ \\
Body mass index (kg m$\left.{ }^{-2}\right)$ & $20.0 \pm 3.0$ & $20.90 \pm 2.6$ & $\mathrm{NS}$ \\
Former smoker $(\%)$ & 15.3 & 6.5 & $\mathrm{NS}$ \\
Day of delivery (day) & $279.6 \pm 8.1$ & $274.0 \pm 8.2$ & $\mathrm{NS}$ \\
Birth weight (g) & $3141.2 \pm 347.0$ & $3130.6 \pm 331.2$ & $\mathrm{NS}$ \\
Cesarean section delivery (\%) & 14.7 & 22.4 & $\mathrm{NS}$ \\
\hline
\end{tabular}

Abbreviation: NS, not significant.

Values are means \pm s.d. unless otherwise noted.

\section{Arterial compliance and brachial PWV}

Baseline brachial artery compliance was calculated as $\Delta V / \Delta P$, where $V$ is the cross-section of the brachial artery and $\Delta V$ is the variation in the cross-section from end diastole to peak systole. $\Delta P$ is the change in brachial pulse pressure from systolic to diastolic pressure. Brachial artery pulse wave velocity (bPWV) was calculated using the following parameters: ${ }^{20}$ bPWV $=1 / \sqrt{ }(\mathrm{DCp})$; $\mathrm{DC}=\left(2 \mathrm{D} \times\right.$ base $\left.\Delta \mathrm{D}+\Delta \mathrm{D}^{2}\right) / \Delta \rho \times$ Dbase $^{2}$. DC is the distensibility coefficient expressed in $10^{-3}$ per $\mathrm{kPa}, \rho$ is the density of blood (assumed to be $1060 \mathrm{~kg} \mathrm{~m}^{-3}$ ), Dbase is the end-diastolic brachial artery diameter before cuff inflation, $\Delta \mathrm{D}$ is the difference between end-systolic brachial artery diameters before cuff inflation and $\Delta \rho$ is the pulse pressure in kPA. ${ }^{16}$

\section{Heart rate variability}

ECGs were performed after subjects had rested for $5 \mathrm{~min}$ in the supine position before FMD measures using a 3-lead ECG system and converted to R-R intervals using the built-in A/D converter (UNEXEF18G). The ECG was continuously monitored and recorded for $5 \mathrm{~min}$ while the patient was resting in a supine position. ECG data were digitized at a sampling rate of $1 \mathrm{kHz}$, and the $\mathrm{R}-\mathrm{R}$ intervals were sequentially aligned. HRV was analyzed in the time domain and in the frequency domain, and nonlinear analyses (detrended fluctuation analysis (DFA)) were performed with those data. Time domain measures of HRV, including the root mean square of the successive differences (RMSSD) of the R-R interval, were calculated as in a previous study. ${ }^{21}$ The calculated RMSSD was used as a parameter of parasympathetic nervous activity. The spectral powers were calculated for the following respective frequency bands: $:^{22,23}$ high-frequency (HF, $0.03-0.5 \mathrm{~Hz}$ ) power was used as a parameter of parasympathetic activity, and the ratio of low-frequency (LF, $0.03-0.15 \mathrm{~Hz}$ ) power to HF power (LF/HF) was used as a parameter of sympathetic nervous activity, and the total $(0.03-0.5 \mathrm{~Hz})$ power (TP) was used to represent the overall autonomic nervous activity. The DFA is a method that typically shows two ranges of scale invariance that is quantified by two separate scaling exponents to detect some apparent self-similarities. A single DFA coefficient could not represent all time intervals; therefore, the short-term correlation exponent $\alpha 1$ was calculated between 4 and 13 beats, whereas the long-term correlation exponent $\alpha 2$ was calculated for $>13$ beats. ${ }^{21,25}$

\section{Blood pressure}

Arterial BP was measured in clinical settings. BP and heart rate at rest were determined in the supine position with an arm cuff using an automated device (UNEXEF18G, UNEX).

\section{Statistical analysis}

All statistical analyses were performed using a commercial software package (SPSS III for Windows, SPSS, Tokyo, Japan). The normality of distribution of the data was examined with the Kolmogorov-Smirnov test. For those parameters that were not normally distributed (bPWV, mFMD, RMSSD, HF and TP), a logarithmic transformation was performed.

Data were expressed as mean \pm s.d. Student's $t$-test was used to compare base clinical character between nulliparous and multiparous women. Two-way analysis of variance (using parity and trimester of gestation as main factors) and post hoc analysis (with Tukey's multiple comparisons) were used to evaluate changes in factors involved in the regulation of peripheral resistance and the control of hemodynamic adaptation throughout pregnancy. For factors found to significantly differ between groups, separate one-way analysis of

Table 2 Comparison of ages and test weeks between nulliparous and multiparous women throughout pregnancy (nulliparaous/multiparaous)

\begin{tabular}{|c|c|c|c|c|c|c|c|}
\hline \multirow[b]{2}{*}{ Number of test } & \multicolumn{2}{|c|}{ First trimester } & \multicolumn{2}{|c|}{ Second trimester } & \multicolumn{2}{|c|}{ Third trimester } & \multirow[b]{2}{*}{ P-value } \\
\hline & Nulliparous $(\mathrm{N}=26)$ & Multiparous $(\mathrm{N}=22)$ & Nulliparous $(\mathrm{N}=67)$ & Multiparous $(\mathrm{N}=39)$ & Nulliparous $(\mathrm{N}=59)$ & Multiparous $(\mathrm{N}=37)$ & \\
\hline Age (years) & $34.5 \pm 4.6$ & $34.5 \pm 5.3$ & $33.9 \pm 5.3$ & $33.9 \pm 4.1$ & $32.7 \pm 4.8$ & $33.4 \pm 3.8$ & NS \\
\hline Test weeks (week) & $11.1 \pm 2.3$ & $11.7 \pm 2.0$ & $22.4 \pm 3.7$ & $21.8 \pm 3.5$ & $33.2 \pm 3.7$ & $31.8 \pm 3.7$ & NS \\
\hline
\end{tabular}

Abbreviation: NS, not significant.

Values are mean \pm s.d. 
variance (factors parity) were conducted to assess the influence of parity throughout pregnancy. Furthermore, 95\% confidence intervals (CIs) for differences in factors involved in the regulation of peripheral resistance between the two circumstances were calculated in the third trimester. Statistical significance was determined by $P$-values $<0.05$ for main effect and interactions.

\section{RESULTS}

\section{Hemodynamic data}

Maternal systolic BP remained stable until the third trimester. The interaction between parity and gestational trimester and the main effect of parity were not significant for systolic BP. Diastolic BP remained stable until the third trimester. Diastolic BP was significantly higher in nulliparous than in multiparous woman throughout pregnancy $(P<0.05)$. Diastolic BP was significantly higher in nulliparous than in multiparous women in the third trimester (95\% CI for difference, 2.43-9.73). There was no significant interaction between parity and gestational trimester. Heart rate increased from the first trimester to the second trimester and was maintained in the third trimester $(P<0.05)$. The interaction between parity and gestational trimester and the main effect of parity were not significant for HR (Figure 1).

\section{Arterial compliance and bPWV}

Arterial compliance significantly increased from the first trimester to the second trimester and was maintained into the third trimester $(P<0.05)$. The interaction between parity and gestational trimester and main effect of parity were not significant for arterial compliance. The bPWV remained stable until the third trimester. The interaction between parity and gestational trimester and main effect of parity were not significant for bPWV (Figure 2).

\section{Arterial diameter and mFMD}

Dinfl and Drep displayed the same changes during pregnancy, whereby they increased from the first trimester to the second trimester and were maintained into the third trimester $(P<0.05)$. Accordingly,
mFMD did not significantly change during pregnancy. The interaction between parity and gestational trimester and main effect of parity were not significant for mFMD (Figure 3).

\section{HRV analysis}

In the analysis of linear parameters, RMSSD was significantly reduced in both groups from first trimester toward to third trimester and was more pronounced in the multiparous group $(P<0.05)$. There was a significant effect of both parity $(P<0.05)$ and gestational trimesters $(P<0.001)$. There was no significant interaction between parity and gestational trimester for RMSSD $(P=0.23)$. RMSSD was significantly lower in multiparous women than in nulliparous women in the third trimester (95\% CI for difference, 0.74-0.34; $(P<0.05)$. There was a significant effect of both parity $(P<0.05)$ and gestational trimester $(P<0.05)$, in addition to a significant interaction between parity and gestational trimester for $\operatorname{HF}(P<0.05)$. When comparisons were performed between each group, HF was found to be significantly reduced in both nulliparous and multiparous women throughout pregnancy $(P<0.05)$, and significantly lower in multiparous women than in nulliparous women in the third trimester ( $95 \%$ CI for difference, 0.15-0.56). This interaction indicates that the most profound effect was in multiparous women during the third trimester. The LF/HF ratio was significantly increased in both groups from the first trimester to the third trimester $(P<0.05)$. The interaction between parity and gestational trimester and main effect of parity were not significant for the LF/HF ratio. TP values were significantly lower in third trimester compared with the first trimester $(P<0.05)$. The interaction between parity and gestational trimester and main effect of parity were not significant for TP (Figure 4).

In the nonlinear analysis, the DFA values $\alpha 1$ and $\alpha 2$ were significantly increased in both groups but were more pronounced in multiparous women. The interaction between parity and gestational trimester and main effect of parity were not significant for values $\alpha 1$. There was a significant effect of both parity $(P<0.05)$ and gestational trimester $(P<0.05)$, in addition to a significant interaction between parity and gestational trimester for values $\alpha 2(P<0.05)$. When
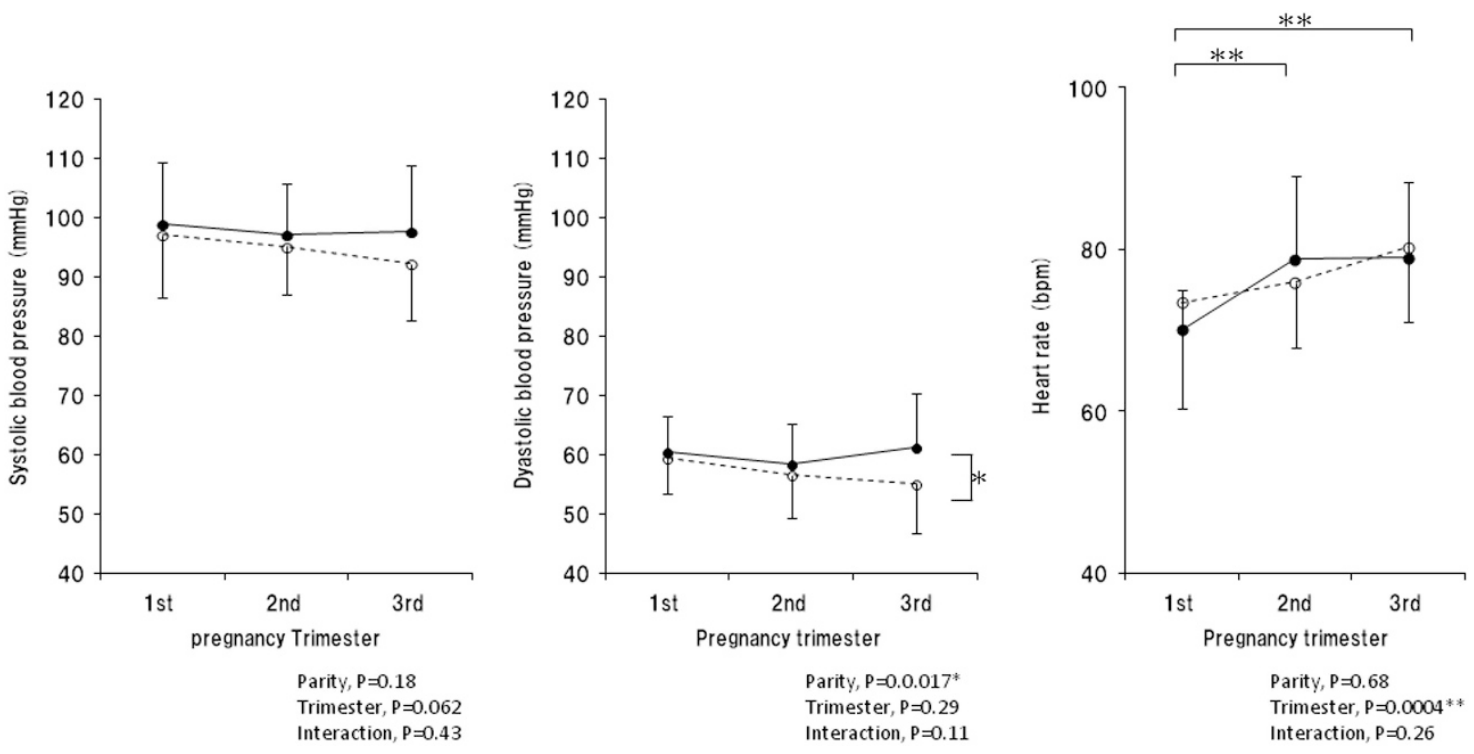

Figure 1 Comparison of systolic blood pressure, diastolic blood pressure and heart rate between nulliparous ( $\square$ ) and multiparous ( $\square$ ) women throughout pregnancy. Results are expressed as mean \pm s.d. for each group. ${ }^{*} P<0.05$ nulliparous women vs. multiparous women; ${ }^{*} P<0.05$ for comparisons between trimesters. 

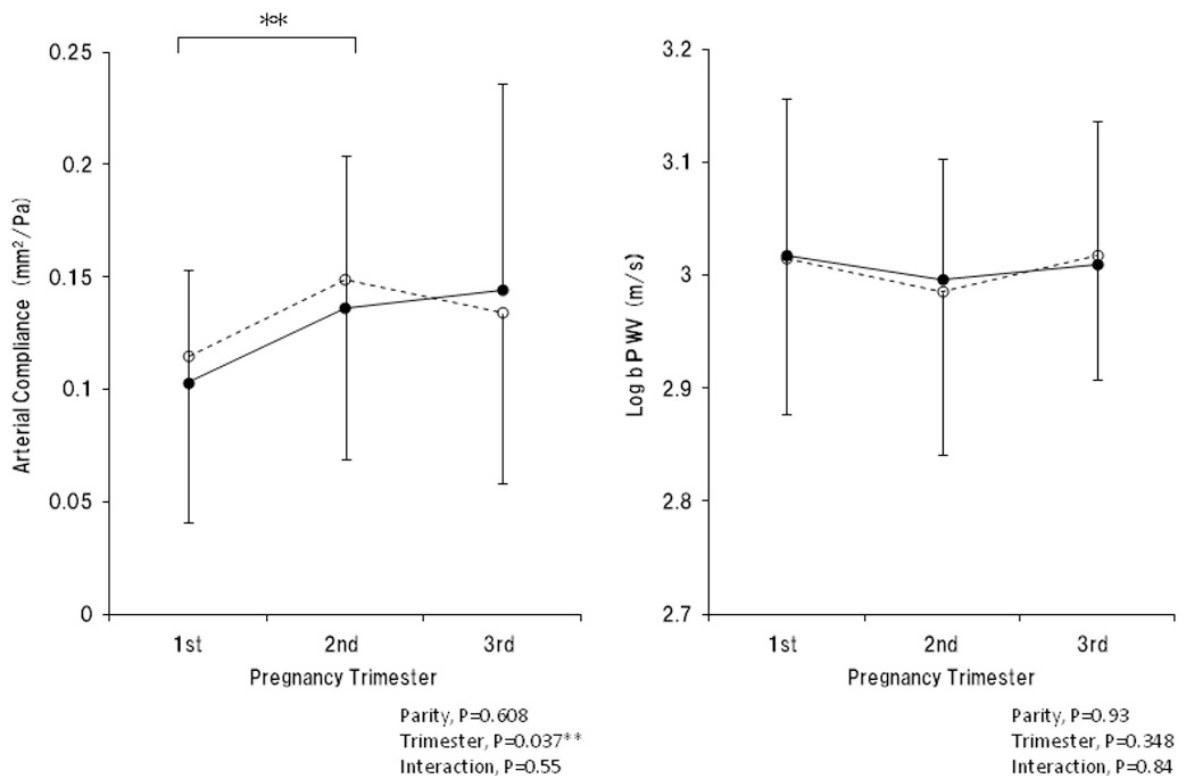

Figure 2 Comparison of arterial compliance and pulse wave velocity (PWV) between nulliparous Results are expressed as mean \pm s.d. for each group. ${ }^{*} P<0.05$ for comparisons between trimesters.

and multiparous $(\square)$ women throughout pregnancy.
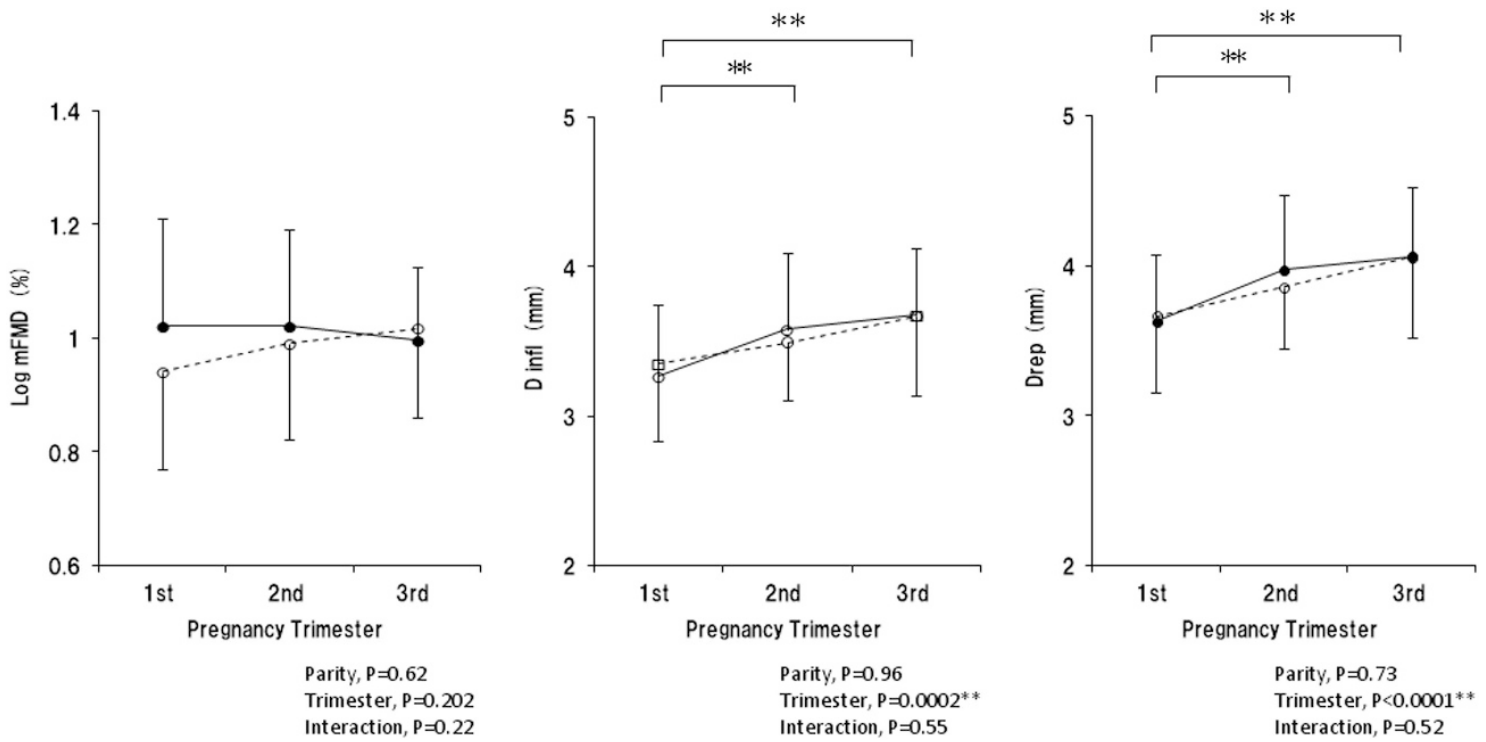

Figure 3 Comparison of modified flow-mediated dilation (mFMD), lowest end-diastolic diameter during cuff inflation (Dinfl) and highest peak end-diastolic diameter during reperfusion (Drep) between nulliparous $* * P<0.05$ for comparisons between trimesters.

analyses were performed for each group, $\alpha 2$ was found to be significantly increased in multiparous women from the first trimester toward the third trimester $(P<0.05)$. However, no significant differences were observed among nulliparous women. In the third trimester, $\alpha 2$ values were significantly lower in nulliparous than in multiparous women (95\% CI for difference, -0.30 to -0.10 ). This interaction indicates that the most profound effect was in multiparous women (Figure 5).

\section{DISCUSSION}

In this study, we evaluated a large series of patients (127 normal pregnancies (nulliparous: 78 vs. multiparous: 49)) that we followed throughout gestation and compared changes in hemodynamic states and peripheral resistance regulatory factors between nulliparous and multiparous women. Despite the limitations of this longitudinal study, our results provide important information about maternal hemodynamic adaptation. Interestingly, we report that nulliparous compared with multiparous women were characterized by greater autonomic nervous activity.

We showed that both maternal hemodynamics and regulatory factors changed dynamically during pregnancy. Based on our results, in pregnant women who do not have any complications, nulliparous compared with multiparous women showed greater autonomic nervous activity and had higher diastolic BP. The third trimester of 

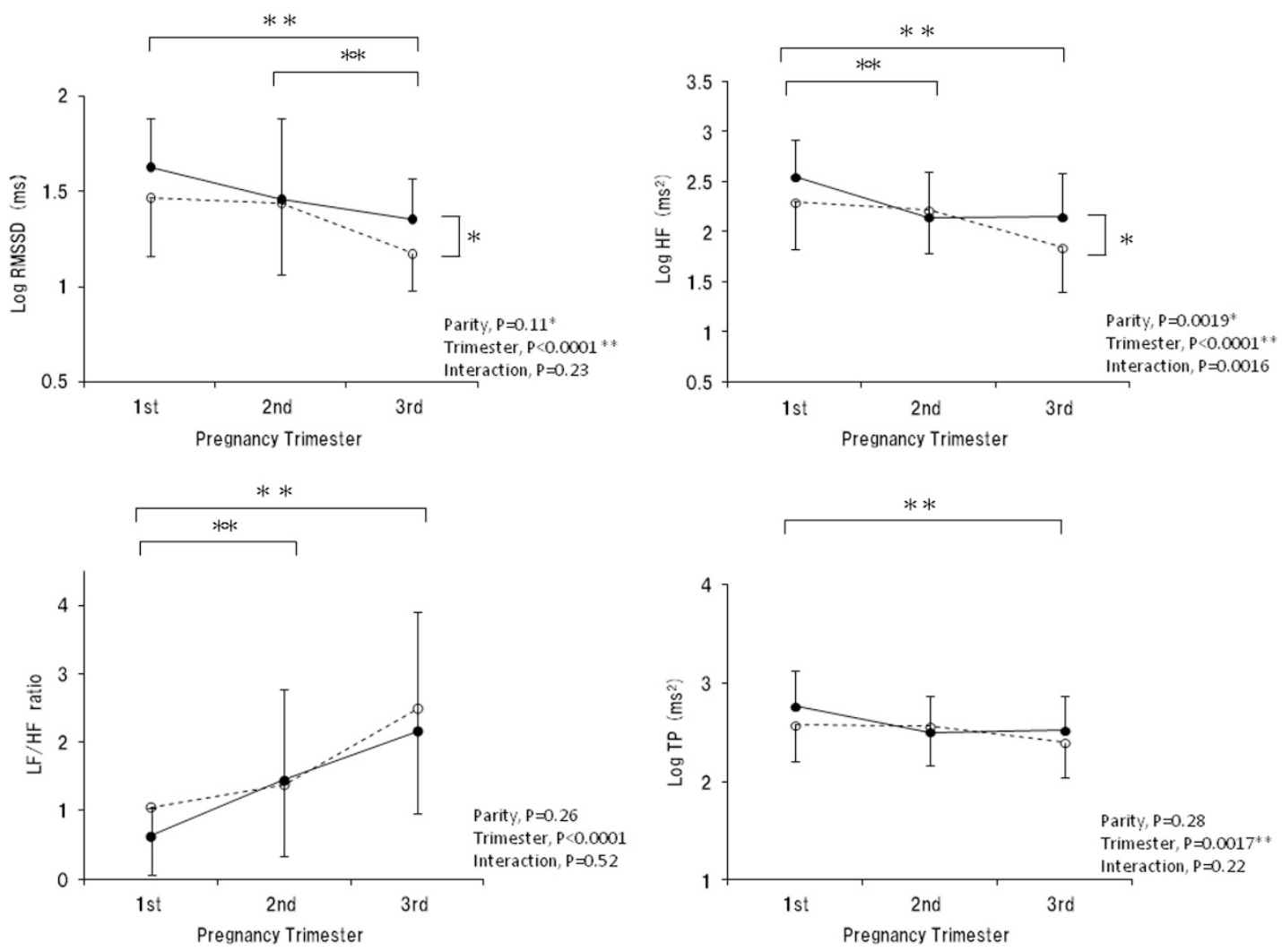

Figure 4 Comparison of linear dynamics (log RMSSD, log LF, log HF, and log TP) between nulliparous ( $\square$ ) and multiparous ( $\square$ ) women throughout pregnancy. HF, high frequency; LF, low frequency; RMSSD, root mean square of the successive differences; TP, total power. Results are expressed as mean \pm s.d. ${ }^{*} P<0.05$ nulliparous women vs. multiparous women; ${ }^{* *} P<0.05$ for comparisons between trimesters.
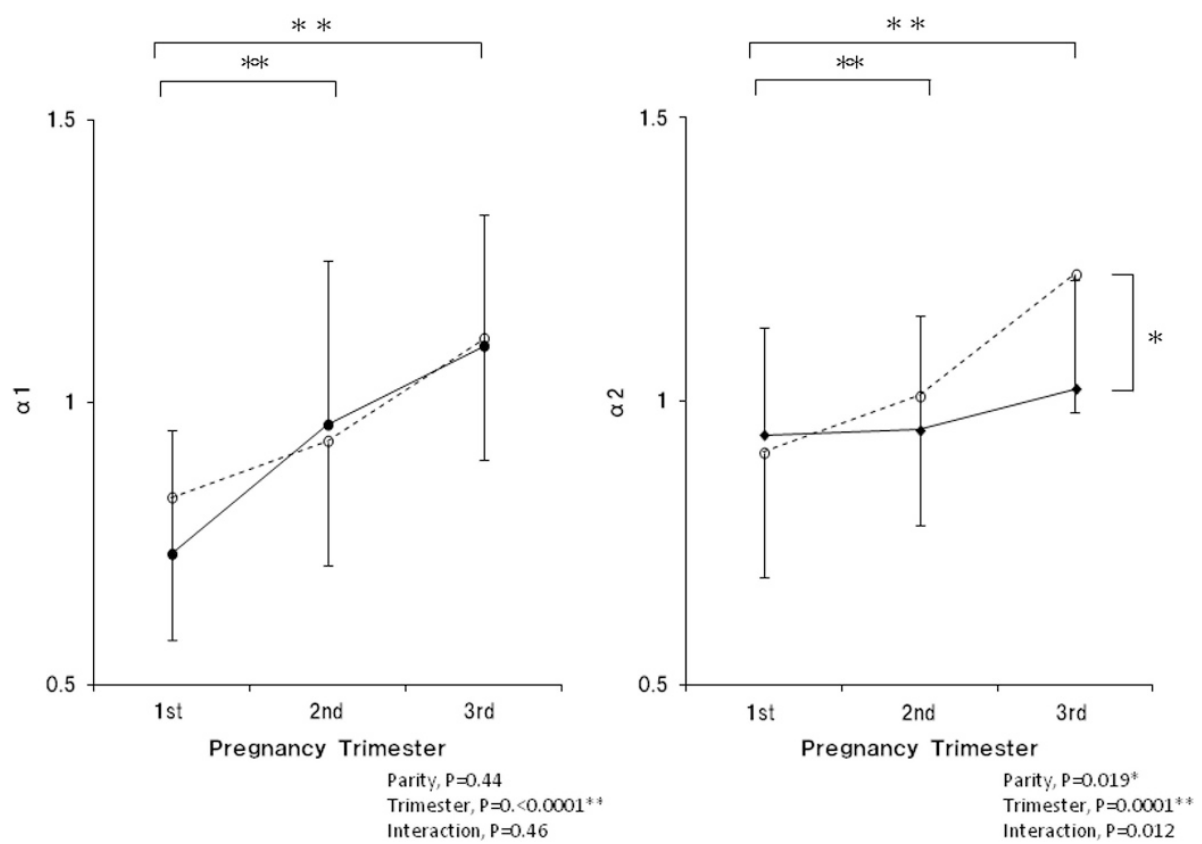

Figure 5 Comparison of nonlinear dynamics ( $\alpha 1, \alpha 2$ : detrended fluctuation analysis (DFA)) between nulliparous $(\square)$ and multiparous ( $\square$ ) women throughout pregnancy. Results are expressed as mean \pm s.d. ${ }^{*} P<0.05$ nulliparous women vs. multiparous women; ${ }^{* *} P<0.05$ for comparisons between trimesters.

pregnancy is the most important time for influence of maternal complication. These are important clinical observations, as cardiovascular maladaptation during pregnancy may lead to gestational hypertension and preeclampsia. Parity might influence these cardiovascular adaptations during pregnancy, especially with respect to autonomic nervous activity. The results of a prospective, population-based cohort study of 8377 women showed higher mean BP levels in nulliparous women as compared with BP levels in 
multiparous women. ${ }^{10}$ Another study of 600 pregnant women showed a greater increase in BP in nulliparous than in multiparous women during pregnancy. ${ }^{7}$ However, not all previous studies showed associations between parity and BP. A small, prospective cohort study of 205 pregnant women did not show differences in BP related to parity. There were no significant differences found in the 24-hour mean systolic and diastolic BPs among nulliparous and multiparous women; ${ }^{8}$ these differences might be explained by the smaller study sample and different measurement methods. The previous studies and the present study suggested that parity had an impact on autonomic nervous activity during pregnancy.

It has been reported that total autonomic nervous activity can be assessed by noninvasive measurement tools. The autonomic nervous system plays a central role in maternal hemodynamic adaptation. Autonomic nervous activity is reduced during pregnancy, with a shift toward less parasympathetic nervous activity and more sympathetic nervous activity. ${ }^{14,26-28}$ Greenwood et al. ${ }^{12}$ used the technique of microneurography and found that, in the third trimester, pregnant women have higher muscle sympathetic nervous activity than do nonpregnant women. The parity impact, previously discussed for autonomic nervous activity, is poorly understood. In this study, we also included a nonlinear analysis of HRV. Nonlinear analyses of HRV were proposed in order to dissect the complex control of heart rate dynamics. ${ }^{18,29,30}$ Normal pregnancy is associated with characteristic hemodynamic changes: increased intravascular volume, cardiac output and heart rate and decreased total vascular resistance. Thus, a nonlinear analysis of HRV is thought to provide additional information about pregnancy. We demonstrated in this study that the DFA values $\alpha 1$ and $\alpha 2$ were significantly increased in both groups and were more pronounced in multiparous women. A previous study reported that DFA is associated with various physiological situations, such as body posture, age, sleep stage and physical activity level. ${ }^{31-33}$ In late pregnant women, the DFA values $\alpha 1$ and $\alpha 2$ were higher than those in nonpregnant women. ${ }^{21,25}$ Our study suggested that the $\alpha 2$ value was significantly lower in nulliparous than in multiparous women in the third trimester. The differences between maternal autonomic nervous adaptations in women could be the result of experience from previous pregnancies. The $\alpha 2$ value was associated with hemodynamic changes. A higher stroke volume and cardiac output and lower total peripheral resistance have been reported in multiparous women compared with those in nulliparous women. ${ }^{1,9,34}$ It is possible that the neurological feedback from expanded vessels led to differences in autonomic nervous activity among nulliparous women. The present study has important implications, and suggests that nulliparous women have greater autonomic nervous activity than do multiparous women.

In previous studies, pregnancy has been reported to be associated with decreased maternal carotid-femoral PWV compared with that in nonpregnant controls. ${ }^{35}$ It is possible that the decreased maternal arterial compliance is related to aberrant maternal physiological and biochemical adaptations. ${ }^{36-38}$ There are few reports on brachial arterial stiffness. The carotid arterial compliance indicated significant stiffening from the first to the third trimesters and that aortic PWV decreased during pregnancy, although no correlation was found between changes among them. ${ }^{11}$ We hypothesized that multiparty would be associated with remodeled systemic arteries and increased arterial compliance. Brachial arterial compliance and PWV are likely to be consequences of parity throughout pregnancy. The previous report suggested that parity is associated with lower carotid artery distensibility. ${ }^{39}$ However, that study did not use maternal data; the study population was aged from 45 to 84 years. Our study included maternal aged women, and arterial stiffness was not significantly different between nulliparous and multiparous women during pregnancy. It is possible that a lot of time is required for arterial remodeling because of parity. The results for maternal FMD have not been consistent among investigators. A study of 71 pregnant women showed that FMD increased beginning in the first trimester, reaching the highest value in the last trimester, and that nitroglycerin-induced dilation was not significantly different between pregnant and nonpregnant women..$^{40}$ Another study of 157 pregnant women showed that FMD was significantly higher in the pregnant women than in the 19 nonpregnant women, but after 30 weeks of gestation, FMD decreased to the levels observed in the nonpregnant women. ${ }^{13} \mathrm{~A}$ longitudinal study of 12 pregnant women demonstrated that FMD increased in the third trimester compared with that in the first and second trimesters and in nonpregnant controls. ${ }^{41} \mathrm{FMD}$ is a simple and noninvasive measure of endothelial capacity and is related to basal arterial diameter at rest. It is possible that the brachial arterial diameter at rest had already been expanded before the occlusion state during pregnancy. Nitric oxide is continuously produced by vascular endothelial cells during pregnancy. ${ }^{13,40,42,43}$ Williams et al. ${ }^{44}$ measured the effect of nitric oxide synthase inhibition on hand blood flow during human pregnancy by venous occlusion plethysmography. They suggested that basal hand blood flow increased significantly during late pregnancy compared with that in the nonpregnant and early pregnant women. In ovariectomized rats, administration of $17 \beta$ estradiol enhanced endothelium-dependent dilation in response to acetylcholine in rats. ${ }^{45} \mathrm{We}$ assessed a variable arterial response to the high flow state during pregnancy. A previous study suggested that mFMD was a complement to FMD in the overall assessment of vascular function. ${ }^{15,16}$ Our study demonstrated that mFMD did not significantly change throughout pregnancy, and there were no significant differences between nulliparous and multiparous women. We also showed that the Dinfl and Drep followed the same changes during pregnancy, in which they increased from the first trimester to the second trimester and were maintained into the third trimester. We suggest that there is no difference in nitric oxide productive capacity between nulliparous and multiparous women throughout pregnancy.

The present study was not longitudinal. Therefore, we cannot exclude the possibility that BP values may result from both autonomic nervous activity and endothelial cell function during pregnancy.

In this study, we made important clinical observations. We showed that parity influences maternal hemodynamic and neurological adaptations during pregnancy. Arterial stiffness and mFMD remained approximately the same between nulliparous and multiparous women for each trimester. An in-depth study of the interactions between maternal autonomic adaptation and hemodynamic control during pregnancy can help clarify the detailed mechanisms involved in the development and progression of preeclampsia.

\section{CONFLICT OF INTEREST}

The authors declare no conflict of interest.

1 Van Oppen A, Carla C, Van Der Tweel I, Alsbach GJ, Heethaar RM, Bruinse HW. A longitudinal study of maternal hemodynamics during normal pregnancy. Obstet Gynecol 1996; 88: 40-46.

2 Moertl MG, Ulrich D, Pickel KI, Klaritsch P, Schaffer M, Flotzinger D, Alkan I, Lang U, Schlembach $\mathrm{D}$. Changes in haemodynamic and autonomous nervous system parameters 
measured non-invasively throughout normal pregnancy. Eur J Obstet Gynecol Reprod Biol 2009; 144: S179-S183.

3 Duvekot JJ, Peeters LL. Maternal cardiovascular hemodynamic adaptation to pregnancy. Obstet Gynecol Surv 1994; 49: S1.

4 Hunter S, Robson SC. Adaptation of the maternal heart in pregnancy. Br Heart J. 1992 68: 540-543.

5 Tkachenko O, Shchekochikhin D, Schrier RW. Hormones and hemodynamics in pregnancy. Int J Endocrinol Metabol 2014; 12: e14098.

6 Mabie WC, DiSessa TG, Crocker LG, Sibai BM, Arheart KL. A longitudinal study of cardiac output in normal human pregnancy. Obstet Gynecol 1994; 170: 849-856.

7 Strevens H, Wide-Swensson D, Ingemarsson I. Blood pressure during pregnancy in a Swedish population; impact of parity. Acta Obstet Gynecol Scand 2001; 80: 824-829.

8 Ayala DE, Hermida RC. Influence of parity and age on ambulatory monitored blood pressure during pregnancy. Hypertension 2001; 38: 753-758.

9 Turan O, De Paco C, Kametas N, Khaw A, Nicolaides K. Effect of parity on maternal cardiac function during the first trimester of pregnancy. Ultrasound Obstet Gynecol 2008; 32: 849-854.

10 Rurangirwa AA, Gaillard R, Steegers EA, Hofman A, Jaddoe VW. Hemodynamic adaptations in different trimesters among nulliparous and multiparous pregnant women; the generation R study. Am J Hypertens 2012; 25: 892-899.

11 Mersich B, Rigó J Jr, Besenyei C, Lénárd Z, Studinger P, Kollai M. Opposite changes in carotid versus aortic stiffness during healthy human pregnancy. Clin Sci 2005; 109 103-108.

12 Greenwood JP, Scott EM, Stoker JB, Walker JJ, Mary DA. Sympathetic neura mechanisms in normal and hypertensive pregnancy in humans. Circulation 2001; 104 2200-2204.

13 Savvidou M, Kametas N, Donald A, Nicolaides K. Non-invasive assessment of endothelial function in normal pregnancy. Ultrasound Obstet Gynecol 2000; 15: 502-507.

$14 \mathrm{Fu} \mathrm{Q}$, Levine BD. Autonomic circulatory control during pregnancy in humans Semin Reprod Med 2009; 27: 330-337.

15 Gori T, Grotti S, Dragoni S, Lisi M, Di Stolfo G, Sonnati S, Fineschi M, Parker JD. Assessment of vascular function: flow-mediated constriction complements the information of flow-mediated dilatation. Heart 2010; 96: 141-147.

16 Harrison M, Parkhurst K, Tarumi T, Lin H, Tanaka H. Low flow-mediated constriction: prevalence, impact and physiological determinant. Clin Physiol Funct Imaging 2011; 31: 394-398.

17 Yuan LJ, Xue D, Duan YY, Cao TS, Zhou N. Maternal carotid remodeling and increased carotid arterial stiffness in normal late-gestational pregnancy as assessed by radio-frequency ultrasound technique. BMC Pregnancy Childbirth 2013; 13 122-2393-13-122.

18 Huikuri HV, Perkiomaki JS, Maestri R, Pinna GD. Clinical impact of evaluation of cardiovascular control by novel methods of heart rate dynamics. Philos Trans A Math Phys Eng Sci 2009; 367: 1223-1238.

19 Voss A, Schulz S, Schroeder R, Baumert M, Caminal P. Methods derived from nonlinear dynamics for analysing heart rate variability. Philos Trans A Math Phys Eng Sci 2009; 367: 277-296.

20 Bjarnegard N, Lanne T. Arterial properties along the upper arm in humans: age-related effects and the consequence of anatomical location. J Appl Physiol (1985) 2010; 108: 34-38.

21 Yeh R, Shieh J, Chen G, Kuo C. Detrended fluctuation analysis of short-term heart rate variability in late pregnant women. Auton Neurosci 2009; 150: 122-126.

22 Miyasaka N, Akiyoshi M, Kubota T. Relationship between autonomic nervous system activity and bone mineral density in non-medicated perimenopausal women. $J$ Bone Miner Metab 2014; 32: 588-592.

23 Ekholm EM, Erkkola RU. Autonomic cardiovascular control in pregnancy. Eur J Obstet Gynecol Reprod Biol 1996; 64: 29-36.

24 Hoshi RA, Pastre CM, Vanderlei LCM, Godoy MF. Poincaré plot indexes of heart rate variability: relationships with other nonlinear variables. Auton Neurosci 2013; 177 271-274.
25 Baumert M, Javorka M, Seeck A, Faber R, Sanders P, Voss A. Multiscale entropy and detrended fluctuation analysis of $Q T$ interval and heart rate variability during normal pregnancy. Comput Biol Med 2012; 42: 347-352.

26 Matsuo H, Inoue K, Hapsari ED, Kitano K, Shiotani H. Change of autonomic nervous activity during pregnancy and its modulation of labor assessed by spectral heart rate variability analysis. Clin Exp Obstet Gynecol 2007; 34: 73-79.

27 Moertl MG, Ulrich D, Pickel KI, Klaritsch P, Schaffer M, Flotzinger D, Alkan I, Lang U, Schlembach $D$. Changes in haemodynamic and autonomous nervous system parameters measured non-invasively throughout normal pregnancy. Eur J Obstet Gynecol Reprod Biol 2009; 144: S179-S183.

28 Walther T, Wessel N, Baumert M, Stepan H, Voss A, Faber R. Longitudinal analysis of heart rate variability in chronic hypertensive pregnancy. Hypertens Res 2005; 28 : $113-118$.

29 Acharya UR, Faust O, Sree V, Swapna G, Martis RJ, Kadri NA, Suri JS. Linear and nonlinear analysis of normal and CAD-affected heart rate signals. Comput Methods Programs Biomed 2014; 113: 55-68.

30 Seely A, Macklem PT. Complex systems and the technology of variability analysis. Crit Care 2004; 8: R367-R384.

31 Castiglioni P, Parati G, Civijian A, Quintin L, Di Rienzo M. Local scale exponents of blood pressure and heart rate variability by detrended fluctuation analysis: effects of posture, exercise, and aging. IEEE Trans Biomed Eng 2009; 56: 675-684.

32 Di Rienzo M, Castiglioni P, Rizzo F, Faini A, Mazzoleni P, Lombardi C, Meriggi P, Parati G. Linear and fractal heart rate dynamics during sleep at high altitude. Methods Inf Med 2010; 49: 521-525.

33 Castiglioni P, Di Rienzo M. Gender related differences in scaling structure of heart-rate and blood-pressure variability as assessed by detrended fluctuation analysis. In 2010 Computing in Cardiology, Belfast, UK. IEEE, 2010, pp 137-140.

34 Hart MV, Morton MJ, Hosenpud JD, Metcalfe J. Aortic function during normal human pregnancy. Obstet Gynecol 1986; 154: 887-891.

35 Macedo ML, Luminoso D, Savvidou MD, McEniery CM, Nicolaides KH. Maternal wave reflections and arterial stiffness in normal pregnancy as assessed by applanation tonometry. Hypertension 2008; 51: 1047-1051.

36 Savvidou MD, Kaihura C, Anderson JM, Nicolaides KH. Maternal arterial stiffness in women who subsequently develop pre-eclampsia. PLOS ONE 2011; 6: e18703

37 Kaihura C, Savvidou MD, Anderson JM, McEniery CM, Nicolaides KH. Maternal arterial stiffness in pregnancies affected by preeclampsia. Am J Physiol Heart Circ Physiol 2009; 297: H759-H764.

38 Lim WY, Saw SM, Tan KH, Yeo GS, Kwek KY. A cohort evaluation on arterial stiffness and hypertensive disorders in pregnancy. BMC Pregnancy Childbirth 2012; 12: 160-2393-12-160.

39 Vaidya D, Bennett WL, Sibley CT, Polak JF, Herrington DM, Ouyang P. Association of parity with carotid diameter and distensibility: multi-ethnic study of atherosclerosis. Hypertension 2014; 64: 253-258.

40 Dorup I, Skajaa K, Sorensen KE. Normal pregnancy is associated with enhanced endothelium-dependent flow-mediated vasodilation. Am J Physiol 1999; 276 H821-H825.

41 Faber-Swensson AP, O'Callaghan SP, Walters WA. Endothelial cell function enhancement in a late normal human pregnancy. Aust N Z J Obstet Gynaecol 2004; 44: 525-529.

42 Quinton AE, Cook C, Peek MJ. A longitudinal study using ultrasound to assess flow-mediated dilatation in normal human pregnancy. Hypertens Pregnancy 2007; 26: 273-281.

43 Saarelainen $H$, Valtonen $\mathrm{P}$, Punnonen $\mathrm{K}$, Laitinen $\mathrm{T}$, Raitakari OT, Juonala $\mathrm{M}$, Heiskanen N, Lyyra-Laitinen T, Viikari JS, Vanninen E, Heinonen S. Subtle changes in ADMA and $\mathrm{l}$-arginine concentrations in normal pregnancies are unlikely to account for pregnancy-related increased flow-mediated dilatation. Clin Physiol Funct Imaging 2008; 28: 120-124.

44 Williams DJ, Vallance PJ, Neild GH, Spencer JA, Imms FJ. Nitric oxide-mediated vasodilation in human pregnancy. Am J Physiol 1997; 272: H748-H752.

45 Ishibahshi T, Obayashi S, Sakamoto S, Aso T, Ishizaka M, Azuma H. Estrogen replacement effectively improves the accelerated intimal hyperplasia following balloon injury of carotid artery in the ovariectomized rats. J Cardiovasc Pharmacol 2006; 47: $37-45$. 